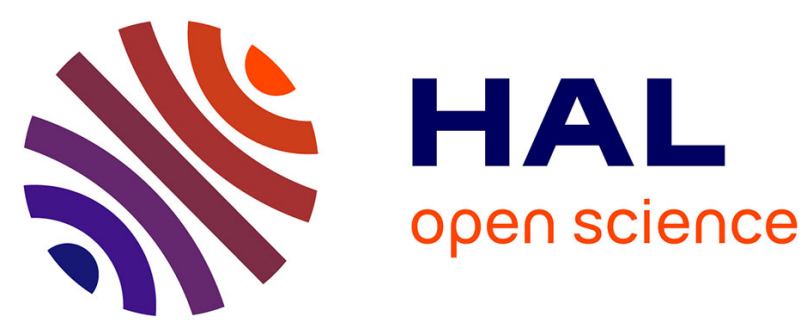

\title{
ULTRASONIC STUDY ON STRAIN RATE SENSITIVITY OF FLOW STRESS IN ALUMINIUM AT STRAIN RATES AROUND 10000/s
}

J. Shioiri, H. Imaizumi, T. Muramatsu

\section{- To cite this version:}

J. Shioiri, H. Imaizumi, T. Muramatsu. ULTRASONIC STUDY ON STRAIN RATE SENSITIVITY OF FLOW STRESS IN ALUMINIUM AT STRAIN RATES AROUND 10000/s. Journal de Physique IV Proceedings, 1991, 01 (C3), pp.C3-177-C3-183. 10.1051/jp4:1991323 • jpa-00250465

HAL Id: jpa-00250465 https://hal.science/jpa-00250465

Submitted on 1 Jan 1991

HAL is a multi-disciplinary open access archive for the deposit and dissemination of scientific research documents, whether they are published or not. The documents may come from teaching and research institutions in France or abroad, or from public or private research centers.
L'archive ouverte pluridisciplinaire HAL, est destinée au dépôt et à la diffusion de documents scientifiques de niveau recherche, publiés ou non, émanant des établissements d'enseignement et de recherche français ou étrangers, des laboratoires publics ou privés. 


\title{
ULTRASONIC STUDY ON STRAIN RATE SENSITIVITY OF FLOW STRESS IN ALUMINIUM AT STRAIN RATES AROUND 10000/s
}

\author{
J. SHIOIRI, H. IMAIZUMI and T. MURAMATSU \\ College of Engineering, Hosei University, 3-7-2 Kajinocho, \\ Koganei-shi, Tokyo 184, Japan
}

\begin{abstract}
Résumé: Des mesures d'atténuation par ultrasons dans des conditions de déformation plastique dynamique ont été faites sur l'aluminium polycristallin à des vitesses de déformation jusqu'à 1200/s. Les résultats sont analysés en considérant la superposition de l'onde ultrasonore avec la déformation dynamique comme un test associant une perturbation de très faible amplitude à celle de très haute fréquence. A partir des résultats de mesures l'influence de la contrainte d'écoulement sur la vitesse de déformation a été évaluée et comparée avec l'influence de la vitesse de déformation obtenue à partir des mesures directes de la contrainte d'écoulement. On discute le rôle de la vitesse de déformation instantanée et de 1'histoire de la déformation dans le front de montée et la sensibilité de la contrainte à la vitesse de la déformation observée au delà d'environ $100 / \mathrm{s}$.
\end{abstract}

\begin{abstract}
Measurements of the ultrasonic attenuation under dynamic plastic deformation are made for polycrystalline aluminium at strain rates up to about $12000 / \mathrm{s}$. The results are analysed regarding the superposition of the ultrasonic wave upon the dynamic deformation as a differential test by a very small amplitude and very high frequency perturbation. From the results of the measurements, the dependency of the flow stress upon the instantaneous strain rate is evaluated and compared with the strain rate dependency of the flow stress obtained from the direct measurements of the flow stress. The roles of the instantaneous strain rate and the strain rate history played in the steep rise in the strain rate sensitivity of the flow stress observed at strain rates above about $5000 / \mathrm{s}$ are discussed.
\end{abstract}

\section{1.- Introduction}

It is widely recognised that the flow stress under dynamic deformation depends upon both the instantaneous strain rate and the strain rate history reflected in the structural state of the matters. The relative importance of these two factors is, however, still under active research especially at high strain rates above about $5000 / \mathrm{s}$ where the steep rise in the strain rate sensitivity of flow stress appears. Ferguson et al. /1/ interpreted the steep rise in the strain rate sensitivity in terms of the transition in the rate controlling mechanism of dislocation motion from the thermally assisted cutting of the point obstacles in the lower strain rate range to the viscous phonon drag in the higher strain rate range. This was the interpretation based upon the role of the instantaneous strain rate, and has been supported by many researchers. While, recently, Follansbee et al. /2/ pointed out the importance of the effect of the strain rate history by measuring the threshold stress (quasi-static yield stress at $0 \mathrm{~K}$ ) after a dynamic pre-deformation. Thus measured threshold stress which can be regarded as a measure of the structure evolution during the dynamic pre-deformation was dependent upon the strain rate of the dynamic 
pre-deformation, and they concluded that the flow stress is mainly due to the structural state reflecting the strain rate history. Further, Follansbee and Kocks /3/ showed that, the flow stress under dynamic deformation measured at the state having the same threshold stress depends little upon the instantaneous strain rate.

In order to clarify the role of the strain rate history in the flow stress, as reviewed by many authors (for examples, Duffy /4/, Harding /5/), a number of works have been done using the differential test technique in which the strain rate is suddenly changed during the deformation. However, those works were done mostly at strain rates below about $2000 / \mathrm{s}$, and could not clarify the role of the strain rate history in the steep increase in the strain rate sensitivity of flow stress which appears at strain rates above about $5000 / \mathrm{s}$. Very recently, Sakino and Shioiri /6/ have made the strain rate change tests for polycrystalline aluminium at strain rates up to as high as about $20000 / \mathrm{s}$ using a newly developed apparatus and showed that the instantaneous strain rate plays a more important role than the strain rate history.

In the present work, another new differential test technique is proposed in which the ultrasonic wave superimposed upon the dynamic deformation is utilised as a differential perturbation. The response to the perturbation is, in this technique, the attenuation and propagation velocity of the ultrasonic wave.

\section{2.- Basic Principle}

In order to obtain time-resolved information on the behaviour of dislocations under dynamic deformation, the authors' group developed the technique for measuring the attenuation and propagation velocity of the ultrasonic pulse superimposed upon the dynamic deformation and made measurements and analyses of results for polycrystalline aluminium deforming at strain rates up to about $7000 / \mathrm{s} / 7,8,9 /$. The theoretical background of the above works was the derivation of an analytical expression for the ultrasonic attenuation and velocity in terms of the dislocation behaviour. The derivation was made using two relationships; (a) the relationship between the flow stress and the strain rate and (b) the relationship between the attenuation and velocity of the superimposed ultrasonic pulse and the stress dependency of the strain rate. Relationship (a) is based upon a kinetic model of dislocation loops while (b) is based upon the continum mechanics. The procedure of derivation combining the above two relationships is very similar to the procedure used in GranatoLucke's work done for the case of static state $/ 10 /$.

In the previous work $/ 7 /$, the ultrasonic attenuation due to dislocations doing glide motion under dynamic deformation, $(\Delta \lambda)_{\mathrm{m}}$ (in logarithmic decrement), was given as

$$
(\Delta \lambda)_{\mathrm{m}}=2 \Omega \mathrm{G}(\mathrm{d} \dot{\varepsilon} / \mathrm{d} \sigma)_{\mathrm{o}} / \mathrm{f},
$$

where $\dot{\varepsilon}$ is the strain rate, $\sigma$ the stress, $f$ the ultrasonic frequency, $\Omega$ the orientation factor, $G$ the shear modulus and subscript o means the state on the basal dynamic deformation upon which the ultrasonic wave is superimposed.

Equation (1) can be written also as

$$
(\mathrm{d} \sigma / \mathrm{d} \dot{\varepsilon})_{0}=2 \Omega \mathrm{G} /\left[(\Delta \lambda)_{\mathrm{m}} \mathrm{f}\right] \text {. }
$$

Equation (2) indicates that the attenuation measurement of the ultrasonic wave superimposed upon the basal dynamic deformation can be used as a differential test to obtain the strain rate dependency of the flow stress by using a small amplitude and high frequency perturbation. In the previous works, the effect of the high frequency perturbation in the structural state caused by the ultra- 
sonic wave was taken into account neither in the kinetic model of dislocations nor in the continuum mechanical relationship between the strain rate dependency of the flow stress and the ultrasonic attenuation and velocity. If the effect of the high frequency perturbation in the structural state is taken into account, by assuming that the amplitude of the ultrasonic wave is very small, the 1 inearised small perturbation theory gives the perturbation stress in terms of the perturbation strain rate by

$$
(\Delta \sigma) \mathrm{e}^{\mathrm{i} \omega \mathrm{t}}=\mathrm{P}(\varepsilon, \dot{\varepsilon})_{0}(\Delta \dot{\varepsilon}) \mathrm{e}^{\mathrm{i} \omega \mathrm{t}}+\mathrm{Q}(\varepsilon, \dot{\varepsilon})_{0} \int(\Delta \dot{\varepsilon}) \mathrm{e}^{\mathrm{i} \omega \mathrm{t}} \mathrm{dt}
$$

where $(\Delta \sigma)$ and $(\Delta \dot{\varepsilon})$ are the amplitudes of the perturbation stress and strain rate, respectively, $\omega=2 \pi f, P()$ and $Q()$ are functions of $\varepsilon$ and $\dot{\varepsilon}$, and again the subscript o means the state on the basal dynamic deformation. The first term in the right hand side of Eq. (3) represents the effect of the high frequency perturbation in the instantaneous strain rate and the second term does the effect of the high frequency perturbation in the structural evolution. Since $\int e^{i \omega t} d t=e^{i \omega t} / i \omega$, the second term is very small at the ultrasonic frequency and, further, its phase differs by $\pi / 2$ from that of the strain rate. Accordingly, the contribution of the second term to the attenuation can be neglected; in other words, the strain rate dependency of the flow stress evaluated from the ultrasonic attenuation data by using Eq. (2) is the contribution of the instantaneous strain rate only and does not include the strain rate history effect.

\section{3. - Experimental Technique}

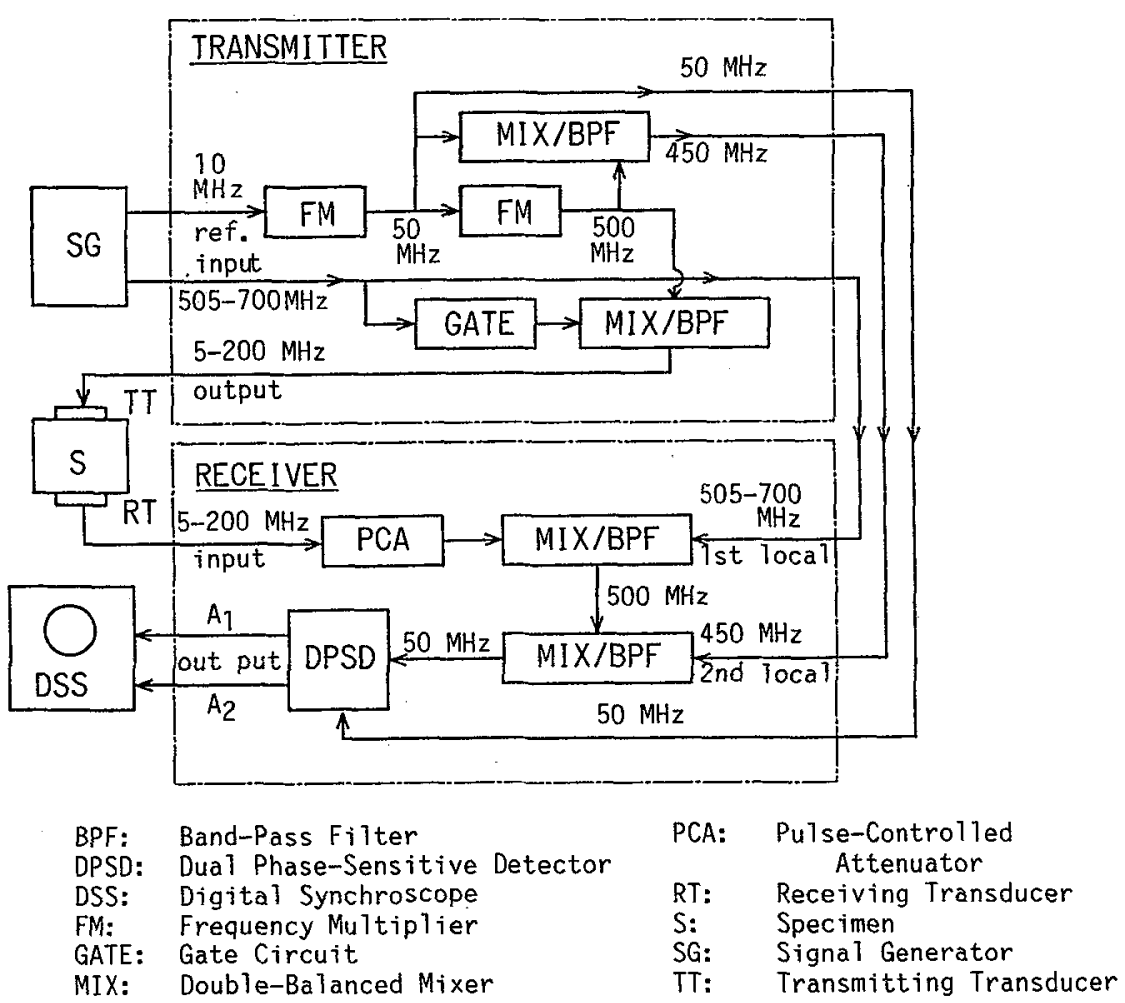

Fig. 1. - Schematic diagram of the newly devised ultrasonic apparatus. 
In the previous works $/ 7,8,9 /$, the ultrasonic measurements were limited at strain rates up to $7000 / \mathrm{s}$ and the problems in the higher strain rate range were treated by extrapolation. However, in order to discuss the steep $r$ ise in the strain rate sensitivity which becomes remarkable at strain rates higher than about $5000 / \mathrm{s}$, the ultrasonic measurement at strain rates around $10000 / \mathrm{s}$ is necessary. For this purpose, a new ultrasonic apparatus shown in Fig. 1 was devised. The principle of the apparatus is the same as the apparatus used in the previous works, but the heterodyne circuit is adopted. The devised apparatus has a high time-resolution capability $(0.7 \mu \mathrm{sec})$ and a wide frequency range ( 5 to $200 \mathrm{MHz}$ ). Further, it has a pulse-controlled attenuator to follow accurately the large and rapid change in the attenuation which appears during the deformation at very high strain rates.

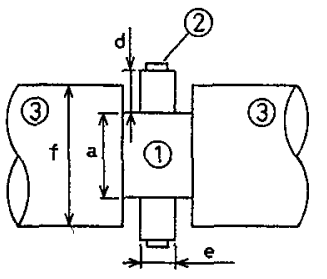

(1) SPECIMEN

(2) TRANSDUCER

(3) HOPKINSON BAR

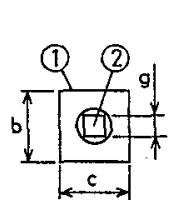

$\begin{array}{clc}\mathrm{a} & 4 & \mathrm{~mm} \\ \mathrm{~b}=\mathrm{c} & 3.3 & \mathrm{~mm} \\ \mathrm{~d} & 2 & \mathrm{~mm} \\ \mathrm{e} & 2 & \mathrm{~mm} \\ \mathrm{f} & 6 & \mathrm{~mm} \\ \mathrm{~g} & 1.4 & \mathrm{~mm}\end{array}$

Fig. 2. - Specimen and set-up around it.

For measurements at very high strain rates, a very small specimen shown in Fig. 2 was used. And, accordingly, very small transmitting and receiving transducers (both $1.4 \times 1.4 \mathrm{~mm}$ ) and a higher ultrasonic frequency $(30 \mathrm{MHz})$ were adopted. Measurements were made for $5 \mathrm{~N}$ purity polycrystalline aluminium (recrystallised at $480 \mathrm{C}$ for $3 \mathrm{hr}$ in a vacuum) at strain rates up to about $12000 / \mathrm{s}$. The experimental procedure and the method of separating the attenuation due to the moving dislocations from the total attenuation measured are the same as in the previous works $/ 7,8,9 /$.

\section{4. - Results}

The results of the measurements of the ultrasonic attenuation due to the moving dislocations are shown in Fig. 3. The results reported in the previous works $/ 7,8,9 /$ are also plotted.

The solid curve in Fig. 3 is the experimental curve for the present results. The dashed curve was predicted in the previous work /9/ by using a kinetic model of dislocation loops in which a regular interval array of the forest dislocations was assumed. In this model the densities of the moving and forest dislocations were also assumed to be independent of the strain rate, and those two densities were determined by fitting the curve to the results of measurements at strain rates up to $7000 / \mathrm{s}$. Therefore, the part of the dashed curve above the strain rate $7000 / \mathrm{s}$ is an extrapolation curve. 


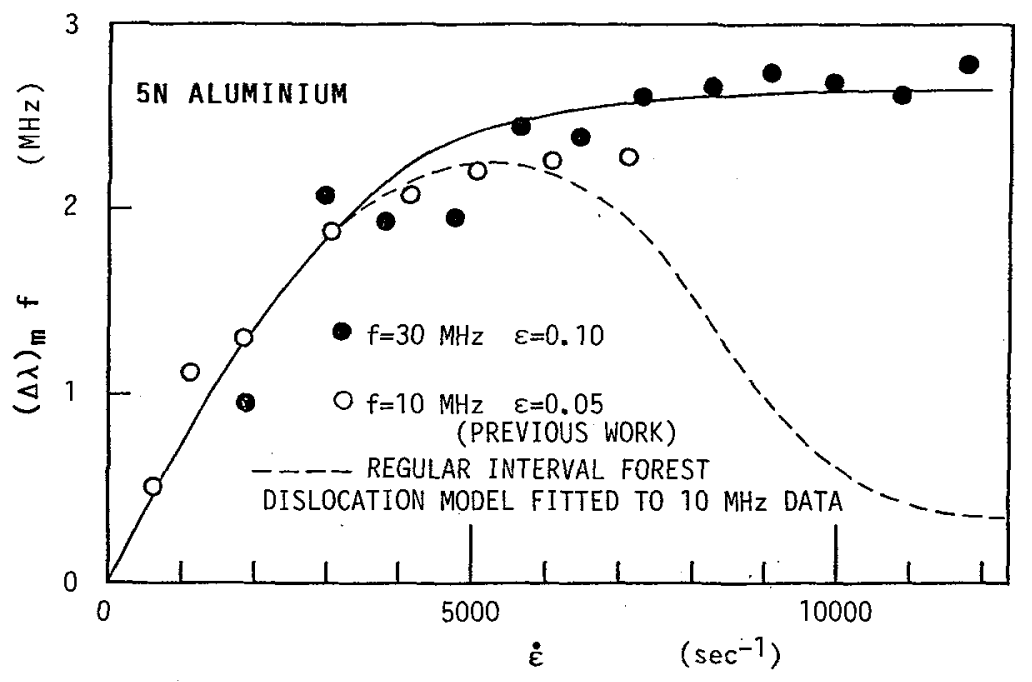

Fig. 3. - Ultrasonic attenuation due to moving dislocations, $(\Delta \lambda)_{\mathrm{m}}$, plotted in the form of $(\Delta \lambda)_{m} f$ vs. $\dot{\varepsilon}$. Data of the previous work are also plotted. Dashed curve is predicted by a kinetic model fitted to the data of the previous work $/ 9 / .(\Delta \lambda)_{m}$ is in logarithmic decrement.

\section{5. - Discussion}

Using Eq. (2), the strain rate dependency of the flow stress was calculated from the ultrasonic attenuation data and is shown in Fig. 4 in the form of the strain rate sensitivity $(\mathrm{d} \sigma / \mathrm{d} \ln \dot{\varepsilon})$. As the ultrasonic data, the experimental curve (solid curve) in Fig. 3 was used. In Eq. (2), the value of the orientation factor $\Omega$ has some uncertainty. In case of polycrystalline materials, in general, exact evaluation of this factor is difficult. In the present case, the ultrasonic attenuation due to the moving dislocations under the basal dynamic deformation is considered. Therefore, the orientation of the active slip system of the dynamic deformation with respect to the propagation direction of the ultrasonic wave becomes an important factor. Taking account of the geometrical condition of Fig. 2, Shioiri and Satoh derived an expression for $\Omega / 11 \%$. Usually, however, this expression gives values a little too high. In the present calculation, 0.04 and 0.06 were used for $\Omega$. These values have been widely used in applying Granato-Lucke's theory to ultrasonic data. In Fig. 4, the strain rate sensitivity evaluated from the results of the direct measurements of the flow stress is also shown. (The results of the direct measurements of the flow stress were reported in reference /6/.)

The strain rate sensitivity evaluated from the directly measured flow stress includes both the effect of the instantaneous strain rate and the effect of the strain rate history, while, as has been already mentioned in the present paper, the strain rate sensitivity calculated from the ultrasonic attenuation data by using Eq. (2) does not include the effect of the strain rate history. Despite of the above difference, the strain rate sensitivity curves of different origin increase rapidly in a similar manner with increasing strain rate. This implies that, although, quantitatively, there is some uncertainty due to the uncertainty in the value of the orientation factor, the instantaneous strain rate plays a very important role in the steep $r$ ise in the strain rate sensitivity observed in the strain rate range above $5000 / \mathrm{s}$. Figure 4 shows that the magnitude of the strain rate sensitivity due to the instantaneous strain rate is about $55 \%$ of the total strain rate sensitivity if $\Omega=0.04$ is assumed and about $82 \%$ if $\Omega=0.06$ is assumed. 


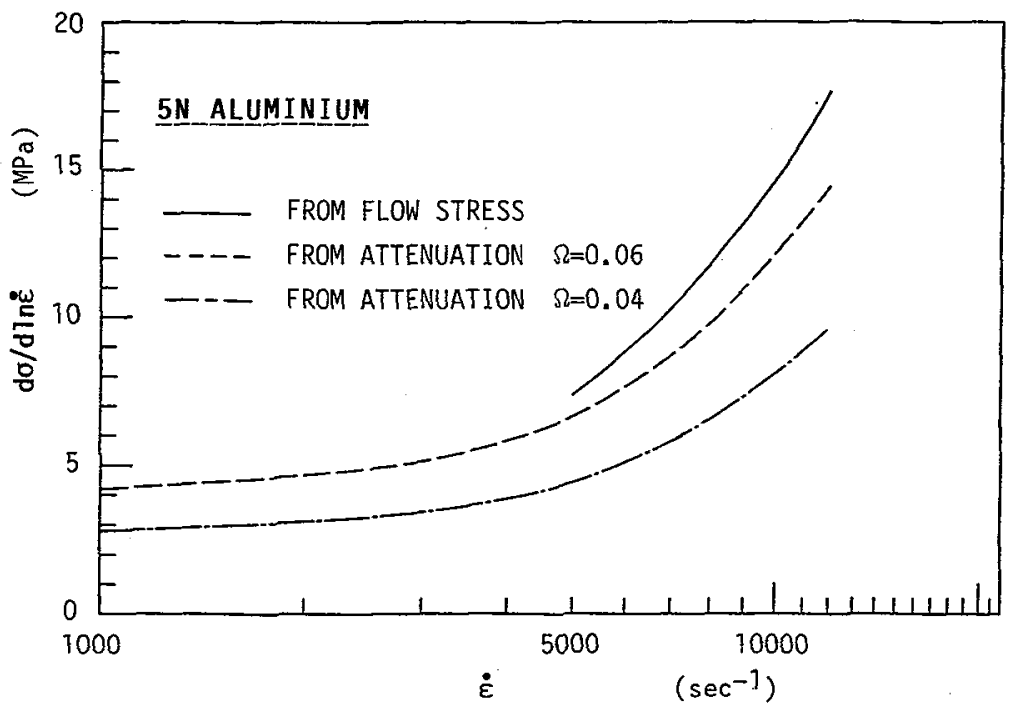

Fig. 4. - Strain rate sensitivity of the flow stress, $d \sigma / d \ln \dot{\varepsilon}$, calculated from the ultrasonic attenuation data. For comparison, strain rate sensitivity obtained by direct flow stress measurements is also shown.

The dashed curve in Fig. 3, which was predicted by the kinetic model of dislocation loops in which a regular interval array of the forest dislocations was assumed $/ 9 /$, falls down at very high strain rate range treated by an extrapolation. As was shown in the previous works $/ 7,8,9 /$, this fall is due to the transition in the rate controlling mechanism from the thermally assisted cutting of the forest dislocations to the viscous phonon drag. However, the attenuation measured in the present work does not show such a drastic fall. This difference is interpreted as follows: in the model the glide dislocation loops hung between adjacent forest dislocations has the same length, and when the strain rate (accordingly flow stress) becomes high all of the glide loops enter simultaneously into the viscous drag-controlled state, while in the real materials, since the array of the forest dislocations should be randon and accordingly the length of the glide loops should have a statistical distribution, such a simultaneous transition will not occur.

\section{6.- Conclusions and Acknowledgement}

The measurements of the attenuation of the ultrasonic wave superimposed upon the dynamic plastic deformation can be regarded as a differential test using a small amplitude and high frequency perturbation in the strain rate. The results of measurements for polycrystalline aluminium at strain rates up to 12000 /s show that the instantaneous strain rate plays a very important role in the steep rise in strain rate sensitivity seen at strain rates above about $5000 / \mathrm{s}$.

Financial support to this work by The Mitsubishi Foundation is gratefully acknowledged.

\section{References}

/1/ Ferguson, W.g., Kumar, A., Dorn, J.E., J. Appl. Phys. 38 (1967) 1836.

/2/ Follansbee,P.S., Kocks, U.F., Regazzoni,G., J. de Phys. 46 (1985) C5-25.

/3/ Rollansbee, P.S., Kocks, U.F., Acta Metal1. 36 (1988) 81. 
/4/ Duffy, J., Materials Behavior under High Stress and Ultrahigh Loading Rates (J.Mescall, V. Weiss, Eds.) Plenum Publishing Corp., New York (1983) 21.

/5/ Harding, J., Mechanical Properties at High Rates of Strain (J.Harding, Ed.) Inst. Phys. Conf. Ser. No.102, Bristol (1989) 189.

16/ Sakino,K., Shioiri,K., Dynamic Flow Stress Response of Aluminium to Sudden Reduction in Strain Rate at Very High Strain Rates, to appear in this issue.

/7/ Shioiri,J., Satoh, K., Mechanical Properties at High Rates of Strain (J.Harding, Ed.) Inst. Phys. Conf. Ser. No.70, Bristol (1984) 89.

18/ Shioiri,J., Satoh, K., Sakino, K., J. de Phys. 46 (1985) C5-3.

/9/ Shioiri,J., Impact Loading and Dynamic Behaviour of Materials (C.Y. Chiem et al., Eds.) DGM Informationsgesellschaft mbH, Adenauerallee (1988) 807. /10/ Granato,A., Lucke, K., J. Appl. Phys. 27 (1956) 583.

/11/ Shioiri,J., Satoh, K., Mechanical Properties at High Rates of Strain (J.Harding, Ed.) Inst. Phys. Conf. Ser. No.47, Bristol (1979) 121. 